\title{
Comparative Study of Three Sedative Techniques During Shock Wave Lithotripsy.
}

\author{
Dr. Wafaa G. Ahmed \\ Department of Anaesthesia and Intensive Care, \\ Faculty of Medicine for Girls, Al-Azhar University
}

\begin{abstract}
:
Background: Many authors found that dexmedetomidine is an effective, safe drug for sedation during extracorporeal shock wave lithotripsy (ESWL). Dexmedetomidine is a lipophilic a2agonist, which sedates patients by reducing sympathetic activity and the level of arousal ,thus patients lie calmly in beds but are easily roused to full consciousness. In the present study, the sedative, haemodynamics, and respiratory effects, and recovery time of dexmedetomidine and dexmedetomidine/fentanyl combination were compared to one of the commonly used sedative analgesic regimen (midazolam/fentanyl) in patients undergoing lithotripsy.

Methods: Sixty ASA I - II patients undergoing (ESWL) were divided into three equal groups and were randomized to receive either dexmedetomidine (dex group), dexmedetomidine fentanyl combination (dex/fentanyl group) or midazolam fentanyl (midazolam/fentanyl group) . In dex group: Initial loading dose of dex $1 \mu \mathrm{g} / \mathrm{kg}$ was infused for $10 \mathrm{~min}$ followed by continuous infusion $0.1-0.7 \mu \mathrm{g} / \mathrm{kg} / \mathrm{h}$. In dex/fentanyl group, initial dose of $1 \mu \mathrm{g} / \mathrm{kg}$ dex was infused over 10 min followed by continuous infusion $0.1-0.7 \mu \mathrm{g} / \mathrm{kg} / \mathrm{h}$. At the same time, fentanyl infusion started $1 \mu \mathrm{g} / \mathrm{kg}$ over $10 \mathrm{~min}$. In midazolam/fenatnyl group, midazolam $0.05 \mathrm{mg} / \mathrm{kg}$ and fentanyl $1 \mu \mathrm{g} / \mathrm{kg}$ were infused over $10 \mathrm{~min}$ followed by continuous infusion of normal saline. Heart rate (HR), mean arterial pressure (MAP), oxygen saturation $\left(\mathrm{SpO}_{2}\right)$, and respiratory rate were recorded. Pain intensity was evaluated with a visual analog scale. Depth of sedation was monitored using Ramsay sedation score (RSS). Recovery time, rescue analgesic and sedative were recorded.
\end{abstract}

Results: In all groups, no significant changes in oxygen saturation and respiratory rate were observed. In dex and dex/fentanyl groups there was a significant decrease in heart rate and mean arterial pressure during and post procedure. Supplemental fentanyl was required in $80 \%$ of patients in dex group to achieve a satisfactory level of analgesia (vs. 25\% of patients in dex/fentanyl group and $40 \%$ of patients in midazolam/fentanyl group). Also $70 \%$ of patients in dex group received rescue midazolam vs. $15 \%$ in dex/fentanyl group and $20 \%$ in midazolam/fentanyl group. Time to home readiness was longer in dex, and dex/fentanyl groups than in midazolam/fentanyl group( 80,75 , and $44 \mathrm{~min})$, respectively.

Conclusion: Dexmedetomidine alone does not appear to be suitable for sedation in patients undergoing ESWL. Combination of dexmedetomidine with fentanyl can be used safely and effectively for sedation and analgesia during ESWL, so it could be an alternative to conventional midazolam/fentanyl regimen but it is associated with longer recovery time.

Keywords; Sedation - Lithotripsy - Dexmedetomidine - Fentanyl - Midazolam. 


\section{Introduction}

Analgesia and sedation are usually required during shock wave lithotripsy (ESWL). Several analgesic/sedative drugs have been used. They may potentially cause respiratory depression, adverse cardiovascular effects and over-sedation with disorientation or confusion (Janzen et al., 1999), so they make these agents less ideal for the intraoperative management of sedation (Zeyneloglu et al., 2008).

Dexmedetomidine is a highly selective $\alpha 2$ adrenergic receptor agonist that has potent sedative properties and has analgesia-sparing properties (Zeyneloglu et al., 2008). Because of these properties (sedation, analgesia and respiratory -sparing), dexmedetomidine might prove useful in (or outside) the operating room

\section{Patients and methods}

Written informed consent was obtained from 60 patients $(22-53 \mathrm{yr})$ ASA I-II scheduled for ESWL. Exclusion criteria included second or third degree heart block, chronic renal failure, history of chronic use of sedatives, history of alcohol or drug abuse, chronic use of $\mathbf{\alpha 2}$ agonists, patients with a current history of psychiatric disorder or presently on psychotropic medications.

In the preoperative holding area before the start of the procedure, patients were instructed on the proper use of the visual analog scale (VAS). On the arrival of patients in the ESWL unit, IV catheter was inserted, a baseline heart rate, noninvasive mean arterial pressure (MAP), respiratory rate (RR) and oxygen saturation $\left(\mathrm{SpO}_{2}\right)$ were obtained and every 5 min during the study period
(OR) for sedation (Al-Hashemi, 2006).

Dexmedetomidine has been widely used in the intensive care unit (ICU) for sedation and postoperative analgesia. It has also been used for sedation during diagnostic and therapeutic procedures (Shahbaz, et al., 2002). It has a distribution half life of approximately $8 \mathrm{~min}$ and a terminal half life of two hours (Hall et al., 2000).

The aim of the present study was designed to compare haemodynamics, respiratory, sedative analgesic effects and the recovery time of dexmedetomidine, and dexmedetomidine/fentanyl to midazolam / fentanyl in patients undergoing (ESWL).

All patients received $4-5 \mathrm{~L} / \mathrm{min}$ oxygen via face mask. The pain of the patients was assessed after the initiation of ESWL and every $10 \mathrm{~min}$ thereafter using VAS ruler from 0-100 mm, zero being no pain and 100 being the worst pain. The predetermined analgesia level was set as VAS $<40 \mathrm{~mm}$. Sedation level was assessed every 10 min using Ramsay sedation scale which is kept at score 3 for adequate sedation (Table1).

In patients randomized to the dex group, an initial loading dose of dexmedetomidine was infused I.V over $10 \mathrm{~min}$ at $1 \mu \mathrm{g} / \mathrm{kg}$ followed by a continuous infusion of $0.1-0.7 \mu \mathrm{g} / \mathrm{kg} / \mathrm{h}$, starting at $0.4 \mu \mathrm{g} / \mathrm{kg} / \mathrm{h}$. In Patients randomized to dexmedetomidine/fentanyl group, initial dose of $1 \mu \mathrm{g} / \mathrm{kg}$ dexmedetomidine was infused over 10 min followed by continuous infusion of 0.1$0.7 \mu \mathrm{g} / \mathrm{kg} / \mathrm{h}$,starting at $0.4 \mu \mathrm{g} / \mathrm{kg} / \mathrm{h}$. 


\section{Dr. Wafaa G. Ahmed}

Simultaneously with the initial dose of dexmedetomidine, fentanyl infusion was started at $1 \mu \mathrm{g} / \mathrm{kg}$ over $10 \mathrm{~min}$.

In dex and dex/fentanyl groups, continuous infusion of dexmedetomidine was titrated every $10 \mathrm{~min}$ in steps of $0.1 \mu \mathrm{g} / \mathrm{kg} / \mathrm{h}$ to

Ramsay sedation scale 3. In patients randomized to midazolam/fentanyl group, midazolam 0.05 $\mathrm{mg} / \mathrm{kg}$ and fentanyl $1 \mu \mathrm{g} / \mathrm{kg}$ were infused over $10 \mathrm{~min}$ followed by continuous infusion of normal saline. The continuous infusions of
Dexmedetomidine and normal saline were terminated $2 \mathrm{~min}$ before the end of procedure.

The patients who were inadequately sedated were given rescue IV doses of midazolam (1mg). Patients having visual analog scale $>40$ have given IV bolus doses of (fentanyl $25 \mu \mathrm{g}$ ). In the recovery room a modified Aldrete score was determined every $5 \mathrm{~min}$ (Table2). Recovery time was defined as the time between discontinuation of drug infusion to the modified Aldrete score of 10 . 
Table (1): Ramsay sedation scores (RSS).

\begin{tabular}{|c|l|}
\hline Score & \multicolumn{1}{|c|}{ Observation } \\
\hline 1 & Anxious, agitated, or restless. \\
\hline 2 & Cooperative, oriented and tranquil. \\
\hline 3 & Responsive to commands. \\
\hline 4 & Asleep, but with brisk response to light glabellar tap or loud auditory stimulus. \\
\hline 5 & Asleep, sluggish response to glabellar tap or auditory stimulus. \\
\hline 6 & Asleep, no response. \\
\hline
\end{tabular}

Table (2): Modified Aldrete scoring system

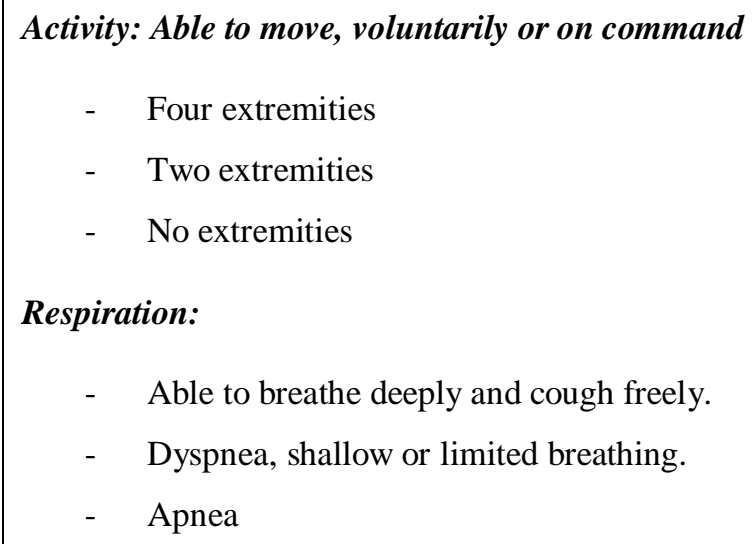

Respiration:

- Able to breathe deeply and cough freely.

- Dyspnea, shallow or limited breathing.

- Apnea

Circulation:

- Blood pressure within $20 \mathrm{mmHg}$ of preoperative level.

- Blood pressure within 20-50 mmHg of preoperative level.

- Blood pressure $\pm 50 \mathrm{mmHg}$ of preoperative level

Consciousness:

- Fully awake.

- Arousable on calling.

- Unresponsive.

Oxygen saturation:

- $\quad$ Saturation $>92 \%$.

- $\quad$ Needs oxygen to maintain saturation $>90 \%$.

- Saturation $<90 \%$ with oxygen

Nine or more points are required for recovery to be confirmed.

\section{Statistical Analysis:}

Results are presented as mean \pm SD. Analysis of variance for repeated measures was performed .
Student's t-test was used to test the difference in means. P-value $<0.05$ was considered statistically significant. 


\section{Results:}

Baseline characteristics of patients and duration of ESWL were similar in all groups (Table3).

Regarding the heart rate no significant differences were found in baseline measurements between all groups. Heart rate showed significant reduction in dex and dex/fentanyl groups $(p<0.05)$ during and after procedure when compared to midazolam/fentanyl group (Fig.1). There were no significant differences in baseline measurements of MAP between the three groups. However dex and dex/fentanyl groups showed significantly lower MAP during and after procedure $(\mathrm{p}<0.05)$ when compared to midazolam/fentanyl group (Fig.2).

No significant changes in oxygen saturation and respiratory rate were observed between all groups during and after procedure. After initiation of ESWLthe mean VAS in dex group was significantly higher than in midazolam/fentanyl group $(\mathrm{p}<0.01)$. On the other hand it was significantly lower in dex/fentanyl group when compared to midazolam/fentanyl group $(\mathrm{p}<0.05)$.

With regard to sedation level, Ramsay sedation score in dex group was significantly lower than midazolam/ fentanyl group $(\mathrm{p}<0.01)$. On the other hand it was significantly higher in dex/fentanyl group when compared to midazolam/fentanyl group.More patients in dex group required rescue fentanyl and midazolam than others groups $(\mathrm{P}<0.05) \quad[$ Table4 \& Fig. 3].Recovery time for patients in dex and dex/fentanyl groups needed to achieve modified Aldert score of 10 was prolonged than midazolam/fentanyl group as shown in (Table 4\& Fig. 3).

Table (3): Demographic data and duration of procedure. Data expressed as mean \pm SD.

\begin{tabular}{|l|c|c|c|}
\hline & Dex group (n=20) & $\begin{array}{c}\text { Dex/fentanyl group } \\
(\mathbf{n = 2 0})\end{array}$ & $\begin{array}{c}\text { Midazolam/fentanyl } \\
\text { group(n=20) }\end{array}$ \\
\hline Age $(\mathrm{yr})$ & $35.65 \pm 10.74$ & $38.75 \pm 7.99$ & $38.7 \pm 8.28$ \\
\hline Sex $(\mathrm{M} / \mathrm{F})$ & $13 / 7$ & $14 / 6$ & $15 / 5$ \\
\hline Weight $(\mathrm{kg})$ & $70.85 \pm 7.63$ & $72.65 \pm 7.10$ & $74.6 \pm 6.89$ \\
\hline ASA I-II & $12 / 8$ & $10 / 10$ & $11 / 9$ \\
\hline Duration of ESWL $(\mathrm{min})$ & 35 & 45 & 40 \\
\hline
\end{tabular}

\section{$\square$ Dex group $\square$ Dex/Fentanyl group $\square$ Midazolam/Fentanyl group}

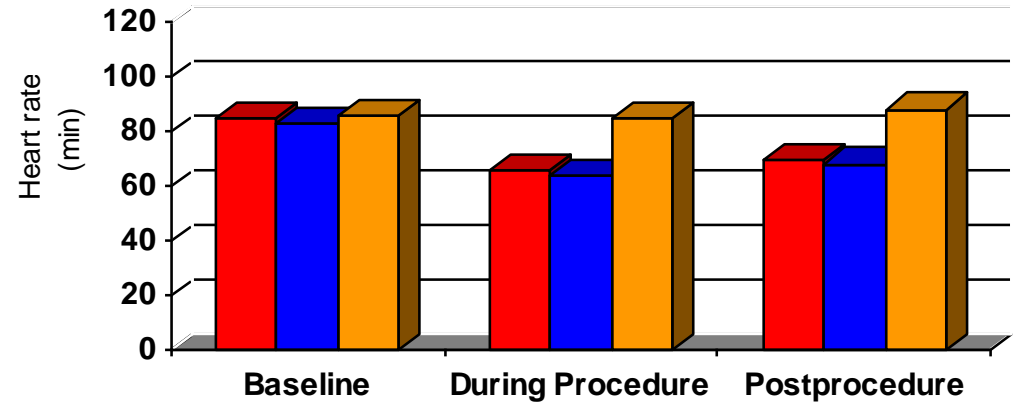

Fig. (1): Heart rate at baseline; during procedure and post procedure of the study groups. 


\section{$\square$ Dex group $\square$ Dex/Fentanyl group $\square$ Midazolam/Fentanyl group}

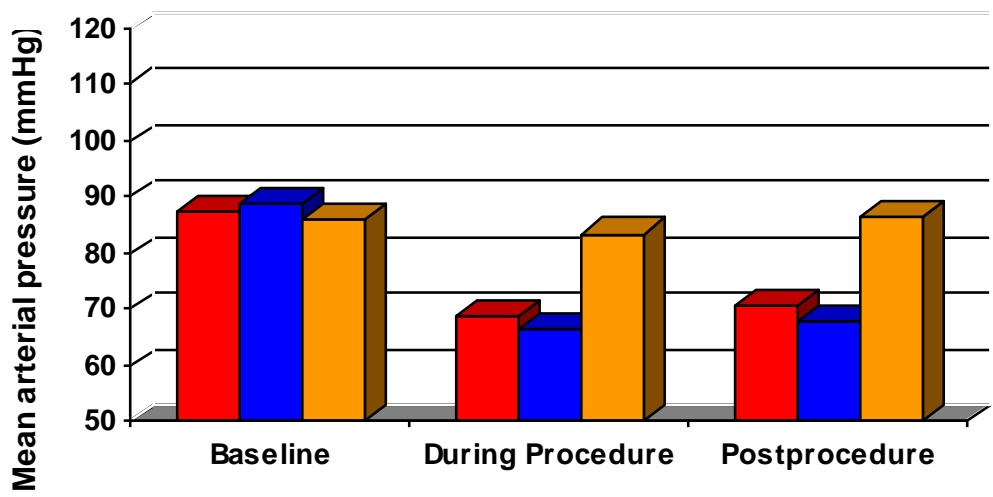

Fig. (2): MAP at baseline; during procedure and post procedure of the study groups.

Table (4): Rescue fentanyl and midazolam (number and \% of patients) and recovery time in all study groups.

\begin{tabular}{|l|c|c|c|}
\hline & Dex group (n=20) & $\begin{array}{c}\text { Dex/fentanyl group } \\
(\mathbf{n = 2 0})\end{array}$ & $\begin{array}{c}\text { Midazolam/fentanyl } \\
\text { group(n=20) }\end{array}$ \\
\hline Rescue fentanyl & $16(80 \%)$ & $5(25 \%)$ & $8(40 \%)$ \\
\hline Rescue midazolam & $14(70 \%)$ & $3(15 \%)$ & $4(20 \%)$ \\
\hline Recovery time (min) & 80 & 75 & 44 \\
\hline
\end{tabular}

$\square$ Dex group $\square$ Dex/Fentanyl group $\square$ Midazolam/Fentanyl group

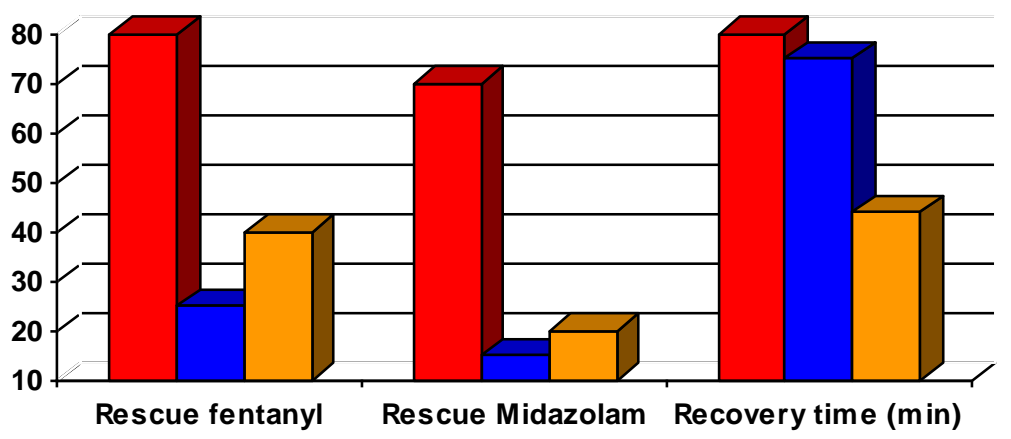

Fig. (3): Rescue fentanyl and midazolam (number and \% of patients) and recovery time (min) in all study groups. 


\section{Dr. Wafaa G. Ahmed}

\section{Discussion:}

The aim of this study was to compare dexmedetomidine and dexmedetomidine /fentanyl to midazolam/fentanyl for sedation and analgesia during lithotripsy (ESWL). The ideal sedative drug should maintain patients ventilation, provide haemodynamic stability, provide patient immobility, and allow easy drug titration. Also ideal sedative drug should ensure rapid induction and recovery while producing a minimal side effect (Koroglu et al., 2006).

It is now well described that dexmedetomidine has analgesia-sparing components when used for sedation in the ICU (Herr, 2000). The results of this study indicate that there is inadequate sedation and analgesia in dex group in comparison to midazolam /fentanyl group, while sedation and analgesia in dex/fentanyl group is better than any other group. These results are similar to that previously reported by Jalowieck et al. (2005).

Also Kaygusuz and his colleagues (2008), found that dexmedetomidine (in combination with fentanyl) may provide advantages over propofol as a sedative drug during ESWL. Controversely, Alhashemy and Kaki (2004) found that dexmedetomidine alone is an effective and safe drug for sedation during ESWL. Also, previous studies supported that infusion of doses of dex (0.1-0.7 ug/kg/h) have provided effective sedation (Hall et al., 2000), (Tobias et al., 2003).

In the present study, the need for rescue analgesia and sedative agents are more in dex group than in any other group. These indicate that dex is not suitable as a sole agent for effective analgesia and sedation during ESWL which was confirmed by the results of (Zeyneloglu et al., 2008).

There was a significant reduction in heart rate and MAP in dex and dex/fentanyl groups when compared to midazolam/fentanyl group. This was attributed to decrease sympathetic outflow and circulating levels of catecholamines. These results are consistent with the results of a pervious study by Triltsch et al (2002).

The associated reduction in HR with dex and dex /fentanyl groups may also be attributed to a vagal-mimetic effect of dexmedetomidine (Jonge et al., 1981). Hypotension and bradycardia have been reported, particularly with large bolus dosing regimens (Bhana et al., 2000).

No significant differences in respiratory rate and $\mathrm{SpO} 2$ were recorded when comparing dex and dex/fentanyl to midazolam/fentanyl group ( $p>0.05)$ which is in agreement with Venn et al., (2000). However, other studies showed some respiratory complications with large and rapid loading dose of dexmedetomidine (Bellevill et al., 1992).

When a dexmedetomidine initial dose was administered rapidly (2 minutes), it caused irregular respiration, apnea, slight hypoxemia, and hypercapnia. (Ebert et al., 2000).

Another important factor influencing the general evaluation of ambulatory practice is rapid home discharge. In this study, the times to discharge readiness were significantly longer when dex was used. This observation reflects the pharmacokinetic properties of dexmedetomidine which has an elimination half life of approximately 2 hours (Ebert et al., 2000). 


\section{Conclusion:}

The sole use of Dexmedetomidine for sedation and analgesia during ESWL is not effective. Combination of Dexmedetomidine and fentanyl provides good pain relief during ESWL

\section{References:}

1- Alhashemi JA (2006): Dexmedetomidine vs midazolam for monitored anaesthesia care during cataract surgery. $\mathrm{Br} \quad \mathrm{J}$ Anaesth, 96 (6):722-6.,

2- Alhashemi JA, KaKi AM (2004): Dexmedetomidine in combination with morphine PCA provides superior analgesia for shock wave lithotripsy. Can J Anaesth, 51: 342-7.,

3-Belleville JP, Wards DS, Bloor BC, Maze M (1992): Effects of intravenous dexmedetomidine in human: sedation, ventilation and metabolic rate. Anesthesiology, 77: 1125-33.,

4- Bhana KNL, McClellan GJ, McClellan KJ (2000): Dexmedetomidine. Drugs; 59: 263-8. ,

5-Ebert TJ, Hall JE, Barney JA, et al. (2000): The effects of increasing plasma concentrations of dexmedetomidine in humans. Anesthesiology, 93: 382-94.,

6- Hall JE, Ulrich TD, Barney JA, et al. (2000): Sedative, amnestic and analgesic properties of small-dose dexmedetomidine infusions. Anesth Analg, 90: 699-705.,

7- Herr DL (2000): Phase III B, multi-center, open label, randomized study comparing the safety/efficacy of dexmedetomidine (Dex) to propofol, for ICU sedation after CABG surgery. Crit Care Med, 28: A $124 .$,

8- Jalowiecki P, Rudner R, Gonciarz M, et al. (2005): Sole use of Dexmedetomidine has limited utility for conscious sedation during outpatient colonoscopy. Anesthesiology, 103 (2): 269-73.

9- Janzen PR, Christys A, Vucevic M (1999): Patient-controlled sedation using propofol in elderly patients in day case cataract surgery. Br J Anaesth, 82: 635.

10- Jonge AD, Timmermans PB, Van Zwieten PA (1981): Participation of cardiac presynaptic $\alpha 2$-adrenoceptors in the bradycardiac effects of clonidine and procedure and can be used as alternative for conventional sedation midazolam/ fentanyl regimen for ESWL but it is associated with prolonged recovery time.

analogues. Naunyn Schmiedebergs Arch Pharmacol., 317: 8-12.,

11-Kaygusuz K, Gokce. G, Gursoy S, et al. (2008): A comparison of sedation with dex or propofol during shock wave lithotripsy: A randomized controlled trial. Anesth Analg, 106: 114-9.,

12-Koroglu A, Teksan H, Sagir O, et al. (2006): A comparison of the sedative, haemodynamic and respiratory effects of dex and propofol in children underfoing magnetic resonance imaging. Anesth Analg, 103: 63-7.,

13-Shahbaz R, Arain,MD, Thomas J, et al. (2002): The efficacy, side effects, and recovery characteristics of dexmedetomidine versus propofol when used for intraoperative sedation. Anesth Analg, 95: 461-6.,

14-Tobias JD, Berkenbosch JW, Russo P. (2003): Additional experience with dexmedetomidine in pediatric patients. South Med J, 96:871-5.,

15- Triltsch AE, Welte M, Von Homeyer P, et al. (2002): Bispectral index-guided sedation with dexmedetomidine in intensive care: randomized, double blind, placebocontrolled phase II study. Crit Care Med, 30: 1007-14.,

16- Venn RM, Hell J, Grounds RM (2000): Respiratory effects of dexmedetomidine in the surgical patient requiring intensive care. Crit Care, 4: 302-8.,

17-Zeyneloglu P, Pirat A, Candan S, et al. (2008): Dexmedetomidine. Causes prolonged recovery when compared with midazolam/fentanyl combination in outpatient shock wave lithotripsy. Europ J Anaesthesiol, 25: 961-7., 


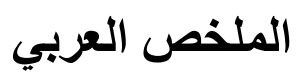

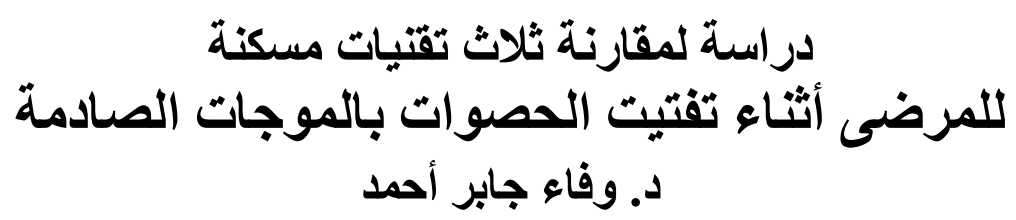

قسم التخدير والعناية المركزة ـ كلية البناتـ جامعة الأزهر

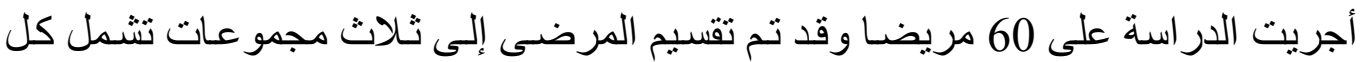

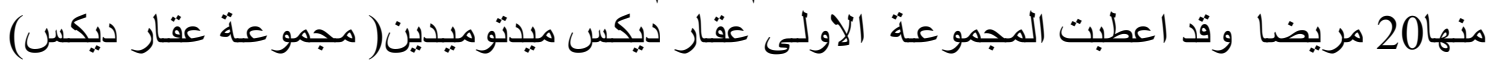

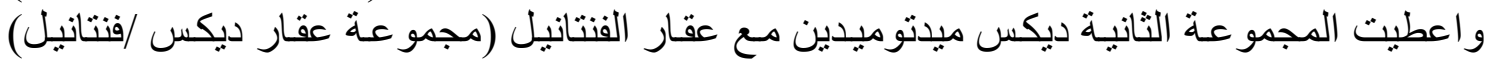

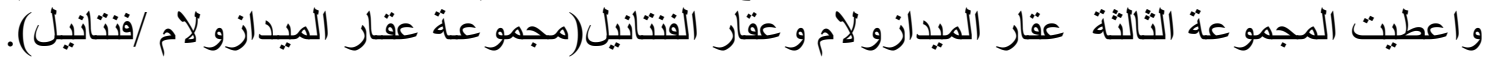

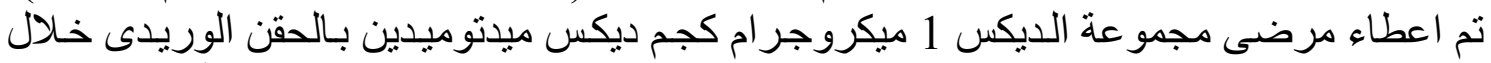

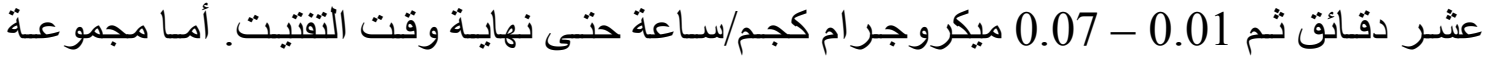

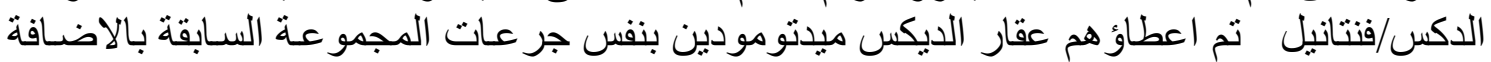

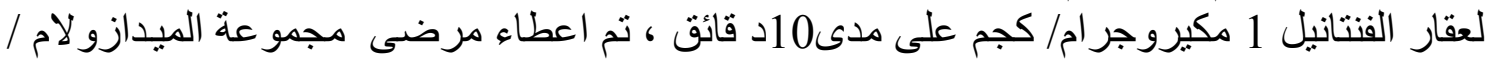

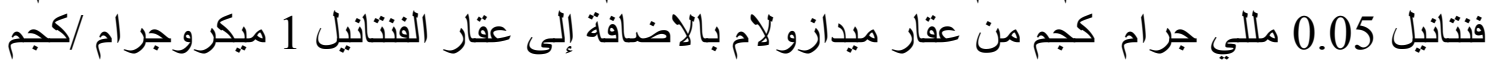

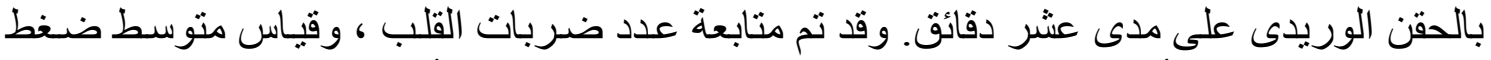

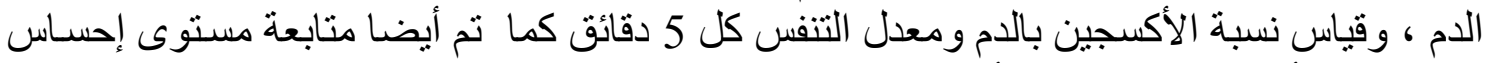

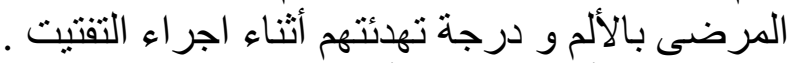

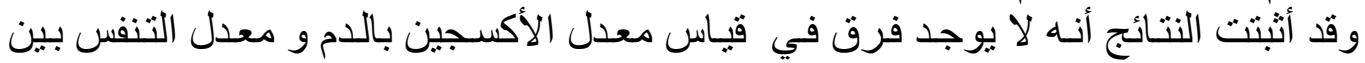

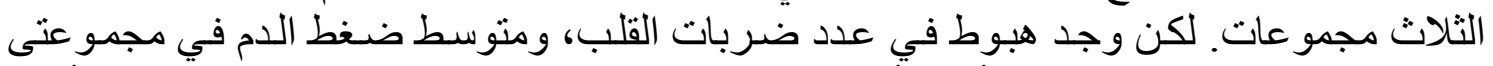

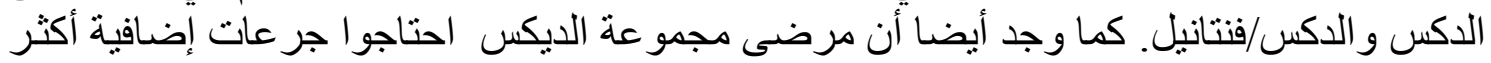

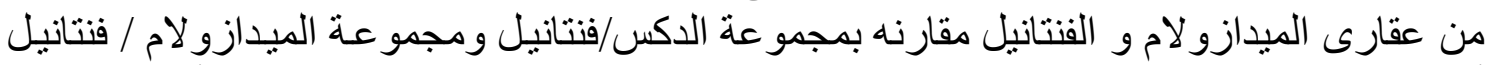

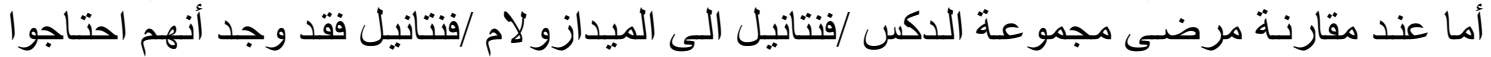

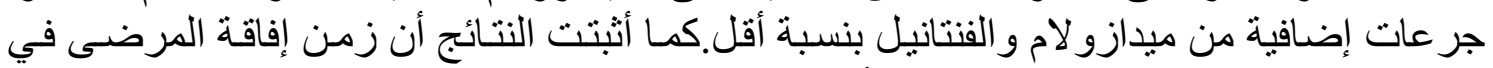
مجمو عتى الديكس و الديكس/فنتانيل كان أطول من مجمو عة الميدازولانلام / فنتانيل.

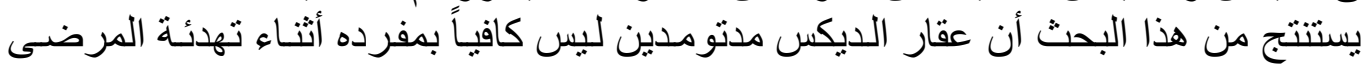

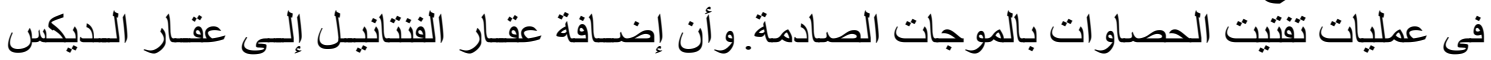

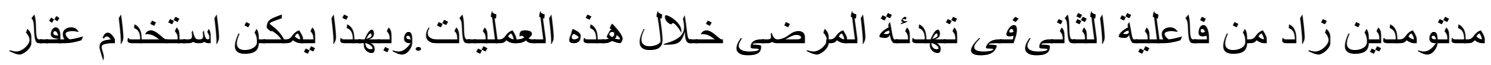

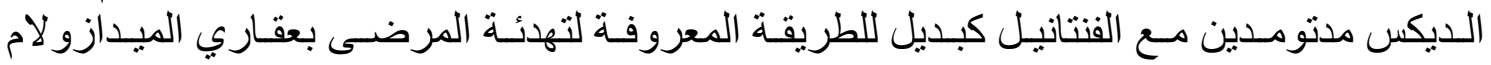

و الفنتانيل. 